\title{
AS REGRAS DA PARTICIPAÇÃO DEMOCRÁTICA: desenho e gargalos jurídico-institucionais dos conselhos de saúde de São Paulo'
}

Henrique Almeida de Castro²

\section{Palavras-Chave}

governança deliberativa / capacidades estatais / direito e democracia / participação institucionalizada / institucionalismo jurídico

\section{SUMÁRIO}

1. Introdução. 2. Brevíssimo percurso institucional da participação em saúde em São Paulo. 3. Os conselhos nos livros. 3.1. A rede de conselhos do município. 3.2. Os conselhos de supervisão. 4. Os conselhos em ação. 4.1. Gargalos jurídico-institucionais na participação em saúde. 4.2. Uma estratégia de evolução institucional. 5. Conclusão. 6. Referências.

' Este artigo apresenta parte dos resultados de pesquisa de iniciação científica financiada pela Fundação de Amparo à Pesquisa do Estado de São Paulo (processo n. 2015/09668-0). Foi anteriormente apresentada no $7^{\circ}$ Encontro da Rede de Pesquisa Empírica em Direito e na Conferência "10 Anos de Mestrado Acadêmico: Direito e Desenvolvimento na FGV Direito SP". Agradeço ao professor Diogo R. Coutinho pela sempre atenciosa orientação. A professora Vera Schattan CoeIho muito gentilmente me aconselhou na delimitação da pesquisa empírica. Contei ainda com comentários dos queridos amigos Daniel Murata, Marco Antônio Moraes Alberto, Victor Doering, Cecília Barreto e Natan Carbone. Por fim, agradeço imensamente às conselheiras e conselheiros que doaram parte de seus atarefados dias para as entrevistas. Após tantas valiosas contribuições, os erros ainda aqui são inteiramente meus.

2 Doutorando na Faculdade de Direito da Universidade de São Paulo e membro do grupo Direito e Políticas Públicas.

\section{Resumo}

O artigo busca mapear e criticar os arranjos jurídico-institucionais que constituem conselhos gestores das supervisões técnicas de saúde do município de São Paulo. Os conselhos compõem a ecologia de instituições participativas brasileiras, as quais se proliferaram no regime pós-redemocratização. De um ponto de vista teórico, parte-se do pressuposto de que escolhas jurídicas desempenham um papel constitutivo nessas instituições, impactando as condições reais de legitimidade de seus processos de deliberação. A partir de pesquisa documental e entrevistas, as regras formais e informais dos conselhos são reconstituídas e avaliadas com base nos critérios normativos da teoria democrática deliberativa. A participação na gestão da saúde em São Paulo representa um caso paradigmático no país, tendo em vista seu processo de formação anterior à redemocratização e sua configuração institucional descentralizada. Ainda assim, são detectadas três situações nas quais as escolhas jurídicas vigentes debilitam suas capacidades. Por fim, sugiro uma estratégia de aprimoramento institucional baseada na literatura da "governança experimentalista". 


\section{THE RULES OF DEMOCRATIC PARTICIPATION: legal-institutional design and bottlenecks of São Paulo's health councils}

Henrique Almeida de Castro 3

\section{Key-words}

Deliberative governance / state capacity / law and democracy / institutionalized participation / legal institutionalism

\section{SUMMARY}

1. Introduction. 2. A brief history of institutionalized participation in São Paulo. 3. Health councils in books. 3.1. The city's council network. 3.2. The regional health councils. 4. Health councils in action. 4.1. Legal-institutional bottlenecks in participatory governance. 4.2. A strategy for reform. 5. Conclusion. 6. References.

${ }^{3}$ PhD candidate in the University of São Paulo Law School and member of the Law and Policy Research Group.

\section{Abstract}

The article maps and evaluates the legalinstitutional arrangements that make up São Paulo's regional health councils. Councils are part of Brazil's "ecology" of participatory institutions, which has flourished after the country's return to democracy. Because legal choices play a constitutive role in shaping these institutions, they impact the real-life conditions under which deliberative processes take place - and, by extension, their legitimating capacities. Through documentary analysis and interviews, the article lays out the councils' formal and informal rules and evaluates them by reference to normative deliberative democratic theory criteria. São Paulo's participatory institutions in health policy represents a unique case due to its origins (which predate country's democratization) and its decentralized design. Despite this, three instances in which current legal arrangements undermine its legitimating capacities are pointed out. Lastly, I suggest one strategy for institutional improvement based on the "experimentalist governance" literature. 


\section{Introdução: o direito nas instituições de} deliberação democrática ${ }^{4}$

As décadas que se seguiram à redemocratização foram acompanhadas da multiplicação de inovadoras experiências de participação popular no Brasil: o país tornou-se «um dos mais importantes laboratórios do mundo" na construção de instituições participativas (Gaventa, 2004, p. 8). No entanto, mesmo com o correspondente interesse de cientistas sociais de diversas disciplinas e da imbricação dos arranjos jurídicos na operação destas instituições, juristas raramente as abordaram em perspectivas não dogmáticas. Se a realização das funções das instituições depende da vigência de estruturas jurídicas bem calibradas, tal omissão revela-se problemática. Este trabalho busca encarar essa lacuna a partir de um exercício de mapeamento e crítica das escolhas jurídico-institucionais que constituem os conselhos gestores das supervisões técnicas de saúde do município de São Paulo.

Os conselhos, juntamente com experiências como orçamentos participativos, audiências públicas e conferências nacionais, compõem, na expressão de Pires e Vaz (2012, p. 51), a "ecologia" de instituições participativas do Brasil. Conselhos gestores de políticas públicas ${ }^{5}$ são espaços colegiados permanentes nos quais se realizam reuniões periódicas entre representantes predeterminados da sociedade civil e da administração. Os conselhos integram órgãos da administração direta responsáveis pela formulação e implementação de políticas públicas. Contam, no espaço de competência desses órgãos, com poderes

\footnotetext{
Os apontamentos teóricos e metodológicos trazidos nesta introdu ção estão desenvolvidos mais detidamente em Castro (2017)

${ }^{5}$ Classificados a partir de suas funções e atribuições, existem ainda outros tipos de conselho, como os de direitos e de fundos. Para este trabalho, importam especificamente os conselhos gestores de políticas públicas. Para uma tipologia, ver Lima, Souza e Teixeira (2012)
}

formais de fiscalização, aprovação e formulação das políticas - suas decisões, vale dizer, devem ter caráter vinculante ${ }^{6}$ Como outros tipos de mecanismos participativos, tiveram grande impulso com a ordem jurídica e política da redemocratização7: atualmente, alguns tipos de conselhos existem em praticamente todos os municípios brasileiros ${ }^{8}$.

Mais precisamente, este artigo foca-se nos conselhos gestores das supervisões técnicas de saúde de São Paulo. Como se verá em detalhes, a estrutura institucional da participação em saúde do município é única, entre outros motivos, por ter suas origens muitos anos antes da redemocratização e por seu caráter descentralizado e capilarizado (contando com diversos conselhos regionais e de unidade, e não apenas o municipal). Os conselhos, ainda, têm impactos inclusivos e redistributivos nada triviais na gestão do provimento de serviços públicos de saúde na avaliação de Vera Schattan Coelho (2007, 2013), incorporaram atores antes excluídos dos processos decisórios e contribuíram para a redução das desigualdades entre áreas centrais e periféricas no provimento de serviços.

O trabalho parte do pressuposto de que escolhas de estrutura, apesar de não levarem a resultados necessários, desempenham um papel constitutivo nessas instituições. Partindo da conceituação proposta por Hodgson (2006), entende-se neste trabalho «instituições» como conjuntos de regras estabelecidas e efetivamente seguidas que

5 Para discussões dogmáticas sobre o poder vinculante dos conseIhos, ver, entre outros, Perez (1999, p. 120), Lopes (2000), Cyrino e Liberati (2003, p. 88)

7 Sobre a relação entre novos princípios constitucionais, mudanças institucionais (como a municipalização) e a proliferação de instituições participativas, ver Vitale (2004, p. 239-245)

8 Dentre os municípios brasileiros, 99.3\% contam com conselhos de assistência social (IBGE, 2013, p. 123), enquanto os conselhos de saúde fazem-se presentes em $99.7 \%$ (IBGE, 2014, p. 60). 
estruturam comportamentos. Ao criarem expectativas estáveis de conduta, elas tanto possibilitam como impedem determinadas ações. As regras podem ser formais (ou seja, positivadas no arcabouço jurídico-estatal) ou informais (surgindo de forma intencional ou descoordenada a partir das interações sociais). Regras formais constantemente desobedecidas, na medida em que não moldam comportamentos, não formam

O conceito de instituição sugere que os conselhos, mesmo que não redutíveis às regras que os compõem, não podem ser inteiramente compreendidos sem referência a elas ${ }^{9}$ - as quais podem incluir, por exemplo, quem pode participar, o assunto e escopo da deliberação, o modo em que é conduzida, quando pode ocorrer e o grau de empoderamento do fórum (Fung, 2003). Quando as instituições são formalmente constituídas (como no caso dos conselhos), arranjos jurídico-estatais necessariamente as integram. Dessa forma, pode-se dizer que o direito é uma lente privilegiada para o estudo das instituições, e que o exame dos detalhados arranjos jurídicos contribui para desvelar as especificidades do regime vigente: "não a democracia, mas que tipo de democracia; não o mercado, mas que tipo de mercado" (Unger, 2015, p. 62) ${ }^{10}$.

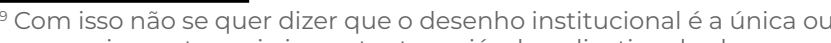
necessariamente mais importante variável explicativa do desempenho dos espaços participativos. Além dela, Faria e Ribeiro (2010:62-66) destacam como estudos brasileiros também têm se voltado a variáveis que denominam política e contextual.

${ }^{10}$ A visão de Unger, que pode ser enquadrada na tradição teórica dos estudos sócio-jurídicos, aproxima explicitamente o pensamento ju rídico de abordagens institucionalistas em outras áreas. Outros teó ricos também notaram as intersecções entre pensamento jurídico e institucionalismos na economia, sociologia e ciência política. Ver, por exemplo, Edelman e Suchman (1996), Santos e Trubek (2006), Smith (2008), Coutinho (2014) e Pistor et al. (2017). Para uma síntese dos institucionalismos em diversas disciplinas, ver Goodin (1998). Com a afirmação de que o direito pode ser visto como uma "lente" para o estudo das instituições, não se quer dizer que juristas operam a partir de uma racionalidade especial e essencialmente distinta daquela de outros cientistas sociais. Significa apenas que, por seu treinamento nas complexidades dos arcabouços jurídicos, estão em posição privilegiada para dar determinadas contribuições ao debate institucional. Longe de excluir outras disciplinas, essa perspectiva aponta para possíveis diálogos entre elas, valorizando os ganhos recíprocos que podem trazer.
}

Os conselhos participativos podem ser descritos como "instituições deliberativas". Em uma definição minimalista", isto significa que sua legitimidade decisória se baseia em processos de comunicação nos quais participantes, refletindo sobre preferências, valores e interesses de relevância comum, buscam justificar mutuamente suas posições (Mansbridge, 2015, p. 29). Determinada decisão poderá ser considerada legítima quando as partes compreenderem seu conteúdo e, mesmo em desacordo com ele, consideremno justificável (Chambers 2003, p. 308). De um ponto de vista normativo, a decisão será mais legítima quanto mais as condições nas quais ocorrem os procedimentos se aproximarem dos requisitos de deliberação ideal - como a "igualdade de participação" (i.e., todos aqueles afetados pela decisão devem dela poder participar ${ }^{12}$. Como aponta Dryzek (1987, p. 661), tais condições não são de fato atingíveis, mas servem como padrão de avaliação das práticas reais.

O direito é um dos elementos que impactam as condições reais das instituições deliberativas, aproximando-as ou distanciando-as das ideais. Nesse sentido, para Levy (2013, p. 368), "leis talvez possam criar procedimentos que desestabilizam normas político-culturais facciosas de tomada de decisão, as quais previamente prejudicavam a deliberação em determinado ambiente". Apesar de a literatura apontar como a deliberação de alta qualidade dificilmente ocor-

\footnotetext{
Além contar com uma longa tradição associada às linhas de pensamento crítico e liberal, a teoria deliberativa despertou amplo interesse acadêmico nas últimas décadas (a ponto de falar-se em uma "guinada deliberativa") (Dryzek, 2000, p. 1-7). Assim, a formulação precisa de suas bases normativas pode variar consideravelmente entre teóricos. A concepção aqui apresentada se alinha com a "negociação deliberativa", proposta Mansbridge et al. (2010). Assim, pensadores clássicos como Jürgen Habermas e John Rawls não receberão atenção neste artigo, apesar de sua importância. Para uma revisão histórica do pensamento deliberativo, ver o artigo de Mansbridge et al.

${ }^{12}$ A formulação dos requisitos de deliberação ideal é um dos temas mais tradicionais na teoria deliberativa. Para uma revisão da literatura e uma útil sistematização de requisitos reconhecidos, ver Almeida e Cunha (2011). O tema será constantemente revisitado no curso do artigo.
} 
re em condições rotineiras, Fishkin (2013, p. 495) considera que cidadãos comuns são capazes de tal diálogo se engajados em desenhos institucionais adequados. Sob tal perspectiva, torna-se possível e desejável mapear as alternativas jurídicas adotadas e as criticar a partir de um ideal normativo (no caso deste artigo, as condições de deliberação ideal). Este exercício, assim, pode revelar escolhas de arranjo que debilitam as capacidades de legitimação das instituições - chamadas aqui, nos termos de Coutinho (2014, p. 296), de gargalos jurídico-institucionais.

Além desta introdução, o artigo divide-se em quatro partes. A próxima contém um brevíssimo histórico do percurso institucional da participação em saúde na cidade, ressaltando suas características únicas em relação a outras experiências no Brasil, bem como seus sucessivos avanços e recuos. Na terceira, apresenta-se um mapeamento do desenho formal da rede de conselhos da cidade, com ênfase no potencial de variação entre os conselhos. Com a quarta, saímos do "direito nos livros" para o "direito em ação", discutindo, com base em uma pesquisa empírica (apoiada em entrevistas semiestruturadas) ${ }^{13}$, o gargalos jurídico-institucionais dos conselhos de supervisão e uma sugestão de estratégia de evolução institucional. Por fim, com base na discussão anterior, a conclusão novamente insiste no significado e potencial de estudos sócio-jurídicos sobre o tema.

\section{Brevíssimo percurso institucional da participação em saúde em São Paulo' ${ }^{14}$}

Foram conduzidas um total de 16 entrevistas semi-estruturadas, com representantes de todos os segmentos dos conselhos, durante 0 primeiro semestre do ano de 2016

${ }^{14}$ Esta parte trata especificamente do caso dos conselhos de saúde do município de São Paulo. Tatagiba (2004) apresenta uma trajetória mais ampla dos conselhos na cidade. Côrtes (1995, p. 69-98) trata do percurso institucional da participação em saúde no país. Apesar de figurar como um de seus protagonistas, os movimentos de saúde da cidade não são o foco do histórico aqui apresentado. Para um trabaIho neles centrado, ver Neder (2001)
Ao contrário da maioria dos municípios no Brasil, os conselhos de saúde de São Paulo não iniciaram sua trajetória institucional com a redemocratização. A maior parte dos conselhos municipais no país foi criada por determinação legal federal15 e contou com formatos copiados de modelos e guias disponibilizados pelo governo federal e órgãos como o Ministério Público e o Tribunal de Contas da União (Almeida e Cunha, 2014). Ao invés de resultarem de uma política da esfera federal, os conselhos de São Paulo tiveram seu início e posteriores reconfigurações a partir de ações e contra-reações recíprocas entre sociedade civil e atores estatais.

As origens dos conselhos estão ligadas à pressão por melhoras nas condições da assistência médico-sanitária da cidade - especialmente na Zona Leste, onde atuavam grupos de donas de casa, pastorais da Igreja Católica e médicos sanitaristas (Jacobi, 1993, p. 42-45; Sader, 1988, p. 261). Esses grupos descobriram então um decreto estadual que determinava a criação de conselhos compostos por "elementos locais" em todos os centros de saúde geridos pelo Estado de São Paulo (Decreto 52.182/69, art. 68). Com esse conhecimento, passaram a demandar da Secretaria de Estado da Saúde a instituição dos conselhos, os quais, por proposta deles, deveriam ter membros eleitos por voto direto e autoridade legal para fiscalizar os centros (Sader, 1988, p. 275).

O primeiro conselho de centro foi instituído em 1979 no bairro Jardim Nordeste. Durante os anos 1980, a secretaria municipal também aceitou a criação de conselhos nos centros por ela geridos, e seu número cresceu gradualmente (Neder, 2001, p. 147).

\footnotetext{
A Lei Federal 8.142/90 passou a exigir a existência dos conselhos de saúde em todos os municípios, e condicionou a isso o repasse de verbas federais para a gestão do SUS.
} 
Com a gestão Luiza Erundina, instituíram-se ainda os conselhos distritais e regionais ${ }^{16}$, bem como o Conselho Municipal de Saúde. Durante esse período de formação, toda a regulamentação encontrava-se disposta em portarias, e são perceptíveis sucessivas transformações na composição, poderes e atribuições dos conselhos - incorporando gestores e trabalhadores da saúde e passando de órgãos unicamente fiscalizatórios para espaços de consulta obrigatória17.

A situação se reverte bruscamente com as gestões Paulo Maluf e Celso Pitta: já em seu primeiro ano, Maluf retira da Câmara o Projeto de Lei 211/91, o qual consolidaria em nível de lei dos diversos conselhos da cidade. Logo em seguida, recentraliza a administração da saúde, extinguindo os distritos e regiões ${ }^{18}$ - e junto com eles, seus conseIhos. Os conselhos das unidades, por sua vez, continuaram a existir, mas de maneira precária (Coutinho, 1997, p. 129-130): os diretores das unidades foram instruídos a deixar de participar das reuniões, e os funcionários passaram a fazer o mesmo por medo de represálias da gestão. O número de conselhos se reduziu, entre 1992 e 1995, de 132 (61\% das unidades em 1992) para 88 (36\% das unidades em 1995). Estas mudanças resultaram

\footnotetext{
No período iniciava-se a implantação municipal do SUS. Uma da diretrizes da gestão era a descentralização intramunicipal da admi nistração da saúde, o que levou à criação de regiões e distritos (Junqueira, 2002, p. 32)

${ }^{7} \mathrm{Nesse}$ sentido, ver os regimentos internos unificados dos conselhos. Conselhos de centro: Portaria SS 44/83, publicada no Diário Oficial do Estado de São Paulo no dia 25/08/03; Portaria SHS 524/84, publicada no Diário Oficial do Município de São Paulo no dia 14/03/84 Conselhos distritais e regionais: Diário Oficial do Município no dia 12/05/92, Diário Oficial do Município no dia 30/06/92. Conselho Municipal de Saúde: Portaria SMS 1.116/89, publicada no Diário Oficial do Município no dia 26/06/89; Portaria SMS 184/92, publicada no Diário Oficial do Município no dia 12/05/92

${ }^{8}$ A gestão Paulo Maluf interrompe implantação do SUS em favor do Plano de Atendimento à Saúde (PAS). O PAS foi uma ampla política de transferência da prestação dos serviços públicos de saúde do município de São Paulo para cooperativas de trabalho médica. As cooperativas, criadas especificamente para esse propósito, assumiram a gestão dos módulos de saúde (a nova divisão administrativa geográfica), dos hospitais, dos postos de pronto socorro e dos postos de assistência. Ao poder público, cabia a fiscalização e o financiamento (Cohn e Elias, 1998). O PAS foi abandonado (e o SUS retomado) na gestão Marta Suplicy.
}

em ampla oposição dos movimentos de saúde (Neder, 2001, p. 161).

A gestão Marta Suplicy, enfim, marcou um retorno à configuração institucional da administração e da participação em saúde na cidade. A diretriz da descentralização foi ao menos superficialmente retomada (este problema será rediscutido no ponto 4.1.2) com a recriação dos distritos de saúde. A Lei Municipal 13.325/02 inseriu pela primeira vez os conselhos das unidades em nível de lei, e reconstituiu os conselhos de distritos. Desde então, o atribulado percurso institucional da participação em saúde se estabilizou: a existência de cada um dos conselhos, juntamente com algumas de suas características essenciais, encontram-se determinados em instrumentos normativos relativamente inflexíveis (leis municipais) e mudanças em suas numerosas regulações infralegais têm operado de maneira incremental (como se verá em mais detalhes).

\section{Os conselhos nos livros}

Finalizada a reconstituição do percurso institucional da participação em saúde no município de São Paulo, esta seção se destina a mapear o atual desenho formal dos conselhos gestores das supervisões de saúde. Em primeiro lugar, traz um panorama da estrutura administrativa da gestão em saúde na cidade e de sua rede de conselhos. Em seguida, explora as diferentes escolhas formais de desenho dos conselhos de supervisão - a quais podem variar, na medida em que cada um tem liberdade para definir seu próprio regimento interno e regulamentos eleitorais ${ }^{19}$.

${ }^{9}$ Para esta reconstituição, foram obtidos 23 regimentos internos e 23 regulamentos eleitorais dentre os 25 conselhos da cidade. Apesar de sucessivas tentativas (em buscas online, contato direto com os conselhos e requerimentos através do sistema e-Sic), não foi possível obter os regimentos internos das supervisões de Santo Amaro/Cidade Ademar e Casa Verde/Cachoeirinha ou os regulamentos eleitorais de Guainases e São Miguel Paulista. 


\subsection{A rede de conselhos do município}

Uma das características mais marcantes da participação em saúde em São Paulo é sua descentralização. Ao contrário da maioria dos municípios, há na cidade não apenas - Conselho Municipal de Saúde, mas uma verdadeira rede de conselhos em diferentes níveis administrativos. Eles atuam de forma autônoma, mas não completamente isolada: têm certo grau de comunicação entre si e compartilham uma burocracia de apoio. Como visto, essa configuração difusa data dos primeiros momentos da evolução dessas instituições na cidade, com a progressiva criação dos conselhos de centro.

Em termos administrativos, o município divide-se territorialmente desde 2005 (gestão José Serra) em coordenadorias e supervisões técnicas (Decreto Municipal 46.209/05). As coordenadorias se subordinam diretamente à Secretaria Municipal de Saúde e abrangem as grandes regiões de São Paulo, existindo seis delas: centro, sul, norte, oeste, sudeste e leste. Cada uma das grandes regiões subdivide-se ainda em diversas supervisões técnicas (substitutas dos distritos), subordinadas às coordenadorias. Elas se estruturam segundo critérios populacionais (Pinto, Spedo e Tanaka, 2009b, p. 1784), e existem atualmente 25 delas. Além das supervisões, há os equipamentos de saúde, instalações de atendimento à população que podem ter diferentes naturezas ${ }^{20}$, como unidades de atendimento básico, centros de referência em DST/AIDS, unidades de tratamento odontológico, centros de tratamento do idoso etc ${ }^{21}$.

\footnotetext{
${ }^{0}$ Como exemplo: a Coordenadoria de Saúde Leste abrange as Super visões Técnicas de Saúde de Cidade Tiradentes, Ermelino Matarazzo, Guaianases, Itaim Paulista, Itaquera, São Mateus e São Miguel Paulista. Apenas a supervisão de Cidade Tiradentes, por sua vez, conta com 20 equipamentos de saúde.

${ }^{21}$ Os hospitais, prontos socorros e postos de atendimento não são de responsabilidade das coordenadorias e supervisões, mas da Autarquia Hospitalar Municipal e das Coordenadorias Hospitalares Regionais (Lei Municipal 14.669/08). Mesmo assim, os hospitais também possuem conselhos gestores.
}

Conselhos existem em três níveis administrativos na cidade de São Paulo: o Conselho Municipal de Saúde (na Secretaria Municipal de Saúde), os Conselhos Gestores das Supervisões Técnicas de Saúde e os Conselhos Gestores dos Equipamentos de Saúde (não há conselhos nas coordenadorias). Dentro de certo espaço, delimitado por instrumentos normativos de hierarquia superior, cada conselho tem autonomia para definir suas próprias regras por meio de seus regimentos internos e regulamentos eleitorais. Mesmo assim, há entre eles ao menos uma forma de hierarquia institucional: os níveis superiores servem como instâncias de recurso das decisões tomadas nos níveis inferiores.

Como se pode perceber, há uma grande quantidade de conselhos no município de São Paulo. Por conta da dificuldade de verificação do funcionamento dos conselhos das unidades, não se conhece precisamente a quantidade deles em operação - no entanto, segundo entrevistados, o número atual ultrapassa 400. Em vista dessa difusão e dos desafios envolvidos em garantir o efetivo funcionamento dessas instituições, foram criados nos últimos anos mecanismos de acompanhamento, fiscalização e assessoramento dessas instituições: existem hoje a Assessoria de Gestão Participativa e as Comissões Interconselhos.

A Assessoria de Gestão Participativa foi criada na gestão Gilberto Kassab, e se insere organicamente no Gabinete do Secretário na Secretaria Municipal de Saúde (e não em qualquer um dos conselhos). $O$ decreto que a instituiu (Decreto 51.600/10), com apenas três artigos, não define sua organização interna, e dispõe a respeito de suas atribuições de forma ampla: acompanhar e apoiar os conselhos da cidade, promover - fortalecimento das entidades da 
sociedade civil voltadas às ações de saúde e acompanhar e apoiar o processo de capacitação de conselheiros. Além da Assessoria da SMS, todas as coordenadorias e supervisões contam com assessores de gestão participativa, os quais cumprem as mesmas funções em suas respectivas regiões ${ }^{22}$.

As Comissões Interconselhos compartilham com a Assessoria a atribuição de acompanhar e apoiar a participação em saúde, mas fazem parte dos conselhos e são compostos por conselheiros. O CMS conta com uma comissão, constituída por 12 membros, desde a entrada em vigor de seu regimento interno, em 2001. Como parte do CMS, ela não o fiscaliza ou assessora, mas atua frente aos conselhos de supervisão e dos equipamentos. Além disso, alguns poucos conselhos de supervisão preveem em seu regimento interno a existência de comissões interconselhos $^{23}$, as quais se ocupam dos conselhos de equipamentos em suas respectivas regiões.

${ }^{3}$ Dos 23 regimentos de supervisão obtidos, apenas os conselhos da Sé, Campo Limpo, Parelheiros e Penha preveem formalmente a Comissão Interconselhos.

\section{FIGURA 1 - ORGANOGRAMA DA REDE DE PARTICIPAÇÃO \\ EM SAÚDE NO MUNICÍPIO DE SÃO PAULO}

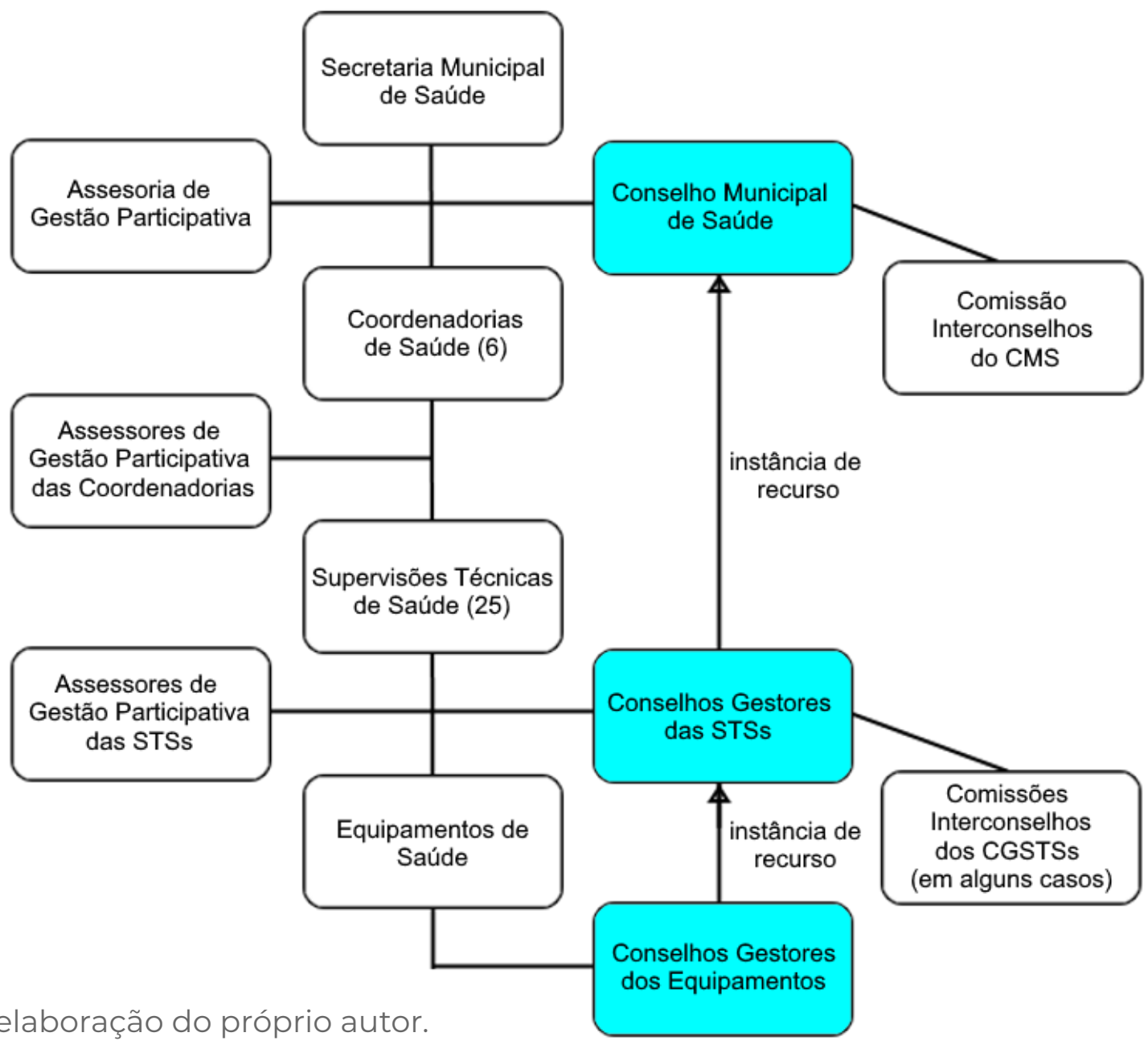




\subsection{Os conselhos de supervisão}

Como se pode ver na Tabela 1, existem hoje uma diversidade de instrumentos normativos aplicáveis aos conselhos de supervisões. Eles variam em termos da esfera federativa responsável, da instituição política correspondente e de seu grau de flexibilidade. Em outras palavras, apesar de contarem com liberdade para definir a maioria de suas regras através de seus próprios regimentos internos e regulamentos eleitorais, existem aquelas que escapam ao controle dos conselheiros. Entre elas, inclui-se a própria definição, em termos bastante vagos, dos conselhos de supervisão: pela legislação municipal, são órgãos "de caráter permanente e deliberativo, destinados ao planejamento, avaliação, fiscalização e controle da execução das políticas e das ações de saúde, em sua área de abrangência" (art. $3^{\circ}$ da Lei Municipal 13.325/02).

\section{TABELA 1 - NORMAS DOS CONSELHOS DAS SUPERVISÕES}

\begin{tabular}{|c|c|c|c|}
\hline \multicolumn{5}{|c|}{ Normas dos conselhos das supervisões } \\
\hline \multirow{2}{*}{ Federais } & Agente responsável & Normas & Caráter \\
\cline { 2 - 4 } & Congresso Nacional & Lei 8.142/90 & Legislativo \\
\cline { 2 - 4 } & Conselho Nacional de Saúde & Resolução CNS 453/12 & Regulamentar \\
\hline \multirow{2}{*}{ Municipais } & Câmara Municipal & Leis 13.325/02 e 13.716/04 & Legislativo \\
\cline { 2 - 4 } & Prefeitura & $\begin{array}{c}\text { Decretos } 42.005 / 02 \mathrm{e} \\
\text { R4.658/04 }\end{array}$ & Regulamentar \\
\cline { 2 - 4 } & Conselho Municipal de Saúde & Resolução 08/04 & Regulamentar \\
\hline \multirow{2}{*}{$\begin{array}{c}\text { Supervisões } \\
\text { de Saúde }\end{array}$} & Conselhos das Supervisões & $\begin{array}{c}\text { - Regimentos internos } \\
\text { - Regulamentos eleitorais }\end{array}$ & Regulamentar \\
\hline
\end{tabular}

Fonte: elaboração do próprio autor.

Em termos de composição, cada conselho deve ter 24 membros plenos e 24 suplentes, sendo metade representantes da sociedade civil, um quarto da administração pública e um quarto dos trabalhadores do sistema de saúde. Além disso, ao menos metade dos representantes de cada segmento deve ter seu gênero declarado como feminino: com a recente Lei Municipal 15.946/13 (regulamentada pelo Decreto 56.021/13), passou a existir cotas para mulheres em todos os conselhos da cidade ${ }^{24}$. Por deter-

24 No caso dos conselhos gestores das supervisões técnicas de saúde pouco deve ter se alterado com a lei, pois, segundo Coelho (2004:259), em 2004 as mulheres compunham 75\% da representação da sociedade civil. minação dos decretos municipais, ainda, os conselhos devem organizar eleições a cada dois anos (o que corresponde à duração do mandato dos conselheiros), as quais devem ser acompanhadas de seus próprios regulamentos eleitorais. Conselheiros podem cumprir apenas dois mandatos consecutivamente.

Em diversas outras matérias, os conselheiros têm liberdade para elaborar suas próprias regras. Entre as variações formais concretamente verificadas incluemse, por exemplo: critérios de seleção de participantes, organização das eleições, 
possibilidade de participação de não conselheiros, existência de comissões temáticas internas, possibilidade de pedido de vistas, forma de coordenação das reuniões, procedimentos de determinação da pauta, ordem dos procedimentos de deliberação internos e quóruns especiais para determinados tipos de decisões. Apesar de muitas vezes partirem de modelos idênticos, existem diferenças visíveis entre algumas alternativas institucionais adotadas. Longe de lidarem apenas com problemas residuais e específicos, tais variações têm potencial para afetar as condições de deliberação dos conselhos.

Um exemplo de variação relevante são os mecanismos para a seleção de participantes. Em situações reais, essa escolha ilustra a dificuldade de cumprimento da condição da "igualdade de participação": dificilmente se consegue incluir todos os impactados por determinada decisão no mesmo ambiente sem que suas contribuições se reduzam a discursos - o "problema de escala" da deliberação (Parkinson, 2006, p. 5). Assim, o problema institucional se torna estabelecer os mecanismos de seleção de participantes mais adequados a cada situação concreta. No caso dos conselhos de supervisão, esse desafio se reflete nas regras das eleições.

A solução mais comum entre os conselhos da cidade consiste em permitir que qualquer cidadão individual residente na região se candidate. No entanto, em outros casos, reservam-se cadeiras a grupos organizados representantes de determinados segmentos sociais (ex.: associações de portadores de deficiências, população negra, movimentos de saúde). Dependendo do critério de legitimidade, ambas as soluções são defensáveis: a

primeira se aproxima de um padrão de democracia liberal agregativa (nos moldes, por exemplo, propostos por Dahl, 2006, p. 63-90), e pode ter o mérito de permitir que qualquer interessado se aproxime do conselho; a segunda segue um padrão de representação de diferenças, podendo garantir a representação de determinados segmentos sociais independentemente da quantidade de votos que conseguem angariar (Young, 2000, p. 121-153)

Outro exemplo ilustra uma variação menos defensável relativa ao problema dos mecanismos de seleção. Em boa parte dos casos, as votações ocorrem através de votos diretos e secretos depositados em urnas abertas. No entanto, em muitos outros, determina-se nos regulamentos eleitorais a seleção por aclamação em plenária. Há dois problemas nessa segunda alternativa: a falta de proteção do voto secreto e o fato de que as eleições devem ocorrer em dias, locais e horários específicos, limitando a possibilidade de comparecimento dos eleitores - em alguns casos, por exemplo, realizam-se durante o período da tarde de dias úteis. Em comparação, cédulas permitem a disponibilização de urnas em diversas unidades de saúde simultaneamente e, muitas vezes, por mais de um dia.

\section{Os conselhos em ação}

Dos 25 conselhos gestores das supervisões técnicas de saúde do município de São Paulo, dois foram selecionados para análise para além de suas estruturas formais. $O$ critério de seleção é simples: possuem desenhos formais consideravelmente diferentes, tanto do ponto de vista de divergências em 
suas opções de regulamentação quanto de seus níveis de detalhamento. O conselho de Campo Limpo conta com um dos regimentos internos mais pormenorizados entre as supervisões. Entre outras questões, ele delimita a estrutura burocrática, procedimentos internos de discussão e atribuições dos conselheiros. Em comparação, o conteúdo do regimento interno do conselho de $\mathrm{Ci}$ dade Tiradentes pouco avança em relação à regulamentação já existente em leis e decretos, deixando maior espaço para acordos e práticas informais.
Cidade Tiradentes e Campo Limpo são ambas regiões periféricas do município de $\mathrm{SP}$, a primeira na zona leste, e a segunda, na sul. Asupervisão de Cidade Tiradentesabarca apenas o distrito de Cidade Tiradentes, na zona leste, e conta com um pouco mais de 200.000 habitantes e 20 equipamentos de saúde. A supervisão técnica de Campo Limpo abrange os distritos de Campo Limpo, Capão Redondo e Vila Andrade, todos localizados na zona sul do município. Os três distritos somam um pouco mais de 600.000 habitantes e 45 equipamentos de saúde.

\section{FIGURA 2 - LOCALIZAÇÃO DAS SUPERVISÕES NO MUNICÍPIO DE SÃO PAULO}

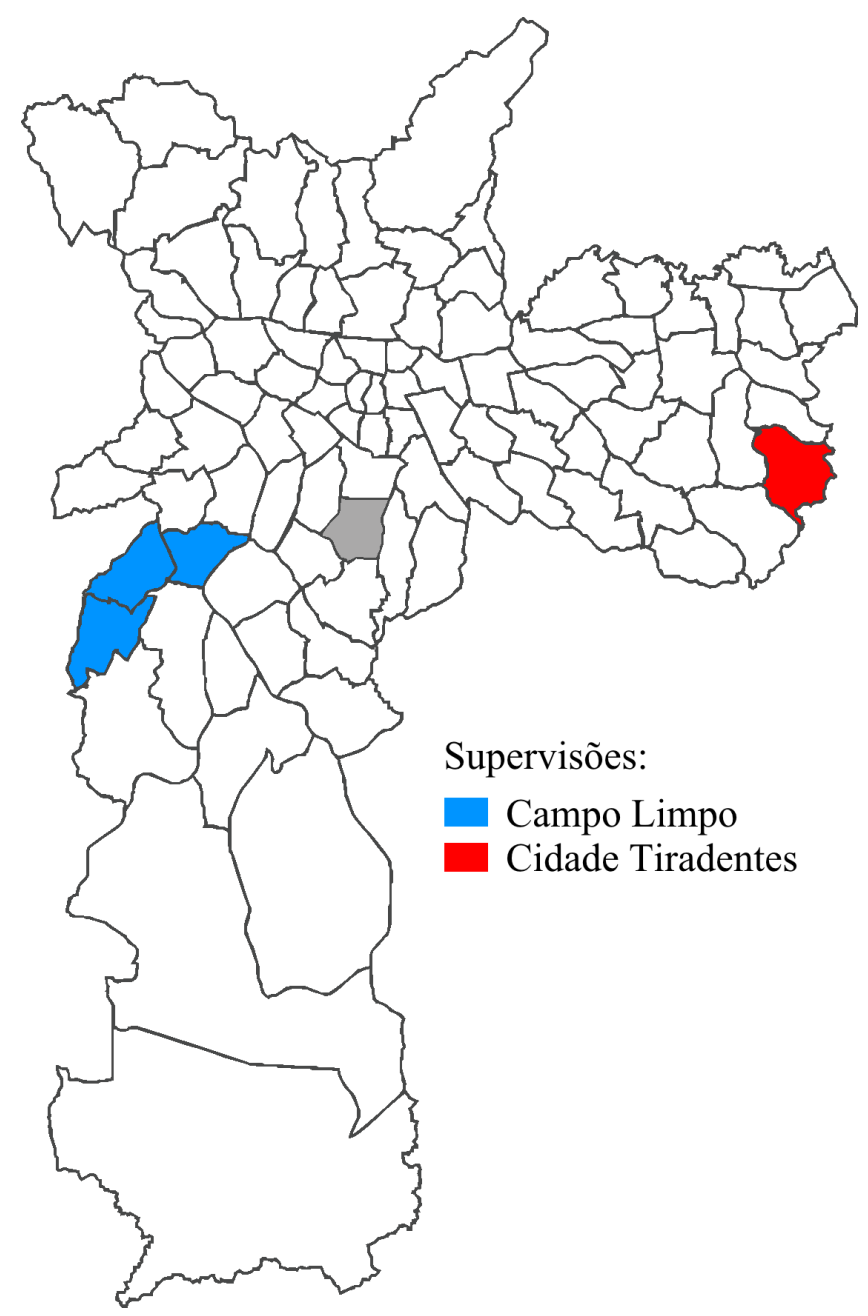

Fonte: elaboração do próprio autor. 
A região de Cidade Tiradentes conta com um movimento de saúde tradicionalmente bem-organizado e, segundo entrevistados, com boas relações entre conselheiros da sociedade civil e gestão. Em sentido contrário, as condições no conselho de Campo Limpo eram paralisantes até uma troca de gestão em 2006. Para entrevistados, o espaço encontrava-se minado por uma administração pouco interessada, falta de organização (atas esvaziadas, falta de local para os encontros, comissões desativadas) e reuniões conflituosas e improdutivas, incapazes de produzirem a cooperação e o diálogo necessários ao funcionamento de uma instituição deliberativa. Como se verá em maiores detalhes adiante, os atuais conselheiros de todos os segmentos têm avaliações positivas do papel dos dois conselhos, e atribuem a suas atuações conquistas na gestão dos serviços de saúde.

Esta etapa da pesquisa incluiu 16 entrevistas semi-estruturadas - 14 com conselheiros de todos os segmentos e 2 com responsáveis pelos órgãos de assessoramento e fiscalização da rede de participação (a Assessoria de Gestão Participativa e a Comissão Interconselhos do CMS). As entrevistas foram montadas com o objetivo de identificar as regras informais dos conselhos e entender sua relação com as formais. Isto significa, por exemplo, reconstituir práticas estabelecidas complementares àquelas dispostas "nos livros", entender quais normas são ignoradas e quais acatadas, bem como verificar situações nas quais as regras formais são simplesmente substituídas por informais ${ }^{25}$. A coleta e análise do material permitiram a identificação de três gargalos jurídico-insti-

\footnotetext{
Nos termos da tradição teórica dos estudos sócio-jurídicos, este tipo de análise remete ao estudo do "direito vivo" (Ehrlich, 1936, p. 493) e a relação entre o "direito nos livros" e o "direito em ação" (Pound, 1910 , p. 15). Sobre as conexões entre esses conceitos clássicos e sua utilidade em estudos empíricos no direito, ver, entre outros, Nelken (1984) e Macaulay (2005).
}

tucionais e a sugestão de uma estratégia de evolução institucional baseada na literatura de "governança experimentalista".

4.1. Gargalos jurídico-institucionais na participação em saúde

Recapitulando rapidamente, gargalos jurídico-institucionais são escolhas de arranjo que debilitam as capacidades de determinada instituição. Para os propósitos deste artigo, importa especificamente a capacidade de legitimação, avaliada nos termos das condições de deliberação ideal formuladas pelos teóricos da democracia deliberativa. O elenco de gargalos aqui disposto limita-se àqueles verificáveis com os métodos adotados, não exaurindo as possibilidades reais. Além disso, vale a ressalva de que, apesar de existirem bons motivos para pensar que afligem todos os conselhos, as entrevistas abarcaram apenas dois deles (além dos órgãos da burocracia de apoio).

4.1.1. O silêncio dos trabalhadores e seu regime de contratação

Um problema amplamente ressaltado em ambos os conselhos é a falta de participação dos trabalhadores durante as discussões. Para os entrevistados, os conselheiros do segmento se manifestam pouquíssimo durante as reuniões, o que prejudica sua representação e a defesa de seus interesses. Todos perceberam, ainda, a mesma causa: o regime de contratação dos trabalhadores empregados pelas entidades privadas que gerem diversos dos equipamentos de saúde.

Ocorre que equipamentos de saúde podem ser geridos não apenas pela administração pública, mas também por entidades privadas (como entidades filantrópicas e hospitais particulares). Isso porque a Secretaria Municipal de Saúde de São Paulo tem em- 
pregado as figuras dos contratos de gestão e de convênio para transferir a algumas delas a administração dos equipamentos (ver Contreiras e Matta, 2015), promovendo o que Maarse (2006, p. 986) denomina de "privatização da gestão"26. Apesar de contarem com fomento estatal (recebem recursos da Secretaria Municipal de Saúde e utilizam as estruturas dos equipamentos de saúde, os quais continuam pertencendo ao município), essas entidades contratam seus próprios empregados. Seu regime de trabalho, dessa maneira, é o celetista, e não o estatutário (dos servidores públicos).

Na questão da participação nos conselhos, a grande diferença entre os dois regimes relaciona-se à estabilidade do trabalhador. Apesar de não contarem com estabilidade garantida em seus cargos específicos (ou seja, há a possibilidade de transferência), os trabalhadores em regime estatutário podem ser demitidos por motivos bastante limitados (por exemplo, quando cometem crime contra a administração pública), e apenas após devido processo administrativo disciplinar, no qual contam com garantia de ampla defesa. Por outro lado, os trabalhadores celetistas podem ser exonerados a qualquer momento. Em São Paulo, a quantidade relativa de celetistas é bastante alta: em abril de 2015, dos mais de 1000 equipamentos de saúde, $67.8 \%$ eram geridos pela iniciativa privada ${ }^{27}$.

Para os entrevistados, a falta de estabilidade garantida impacta fortemente a disposição dos conselheiros trabalhadores contratados

"O sentido de "privatização" aqui trazido tem contornos econômicos e sociológicos e difere de seu uso corrente na literatura jurídica - qual seja, a transferência do poder de controle de determinada entidade, antes integrante da organização administrativa, a um agente privado que não tenha qualquer vínculo especial com a administração pública. Agradeço ao amigo Marco Antônio Moraes Alberto por me chamar atenção nesse ponto.

27 Esta informação foi obtida através de requisição no Sistema Eletrônico do Serviço de Informação ao Cidadão do município de São Paulo (Protocolo n 016966). por entidades privadas em se manifestarem durante as discussões. Isso porque, mesmo sem ameaças, sentem-se em perigo ao discutir problemas de seus equipamentos de saúde, falhas na gerência ou insatisfações com o espaço de trabalho. Muitas vezes, esses conselheiros sequer comparecem às reuniões ${ }^{28}$ :

"Eu vou falar enquanto trabalhadora. Alguns se sentem inibidos por estarem próximos aos seus gestores. Outros sofrem mesmo, porque têm a coragem de falar. Eles sofrem algumas disciplinas. Tem muito gestor que aplica medida em cima do trabalhador, e isso acontece muito nas OSs. Nós já tivemos um trabalhador de OS que foi retirado do local de trabalho, onde ele era um conselheiro excelente. Ele foi transferido para outra unidade, como represália. Com isso, ele abandonou o conselho da supervisão. Aqui, nós temos a maioria dos conselheiros do segmento trabalhador vindos das OSs. Temos 12 trabalhadores, e só três são da administração direta. O restante é das OSs. É difícil". (entrevista com representante do segmento trabalhador)

"Os trabalhadores escondem as coisas. Trabalhador chega aqui, e ai dele se abrir a boca. Quando ele chega na unidade dele, é degolado. Trabalhador não vem pra cá pra colocar nada não, vem só pra assistir. Ele vem pra avisar o que está acontecendo. Eles dão uns avisos, mas ninguém fala do que está acontecendo nas unidades". (entrevista com representante do trabaIhador)

“Não que a gente possa dizer que estava

${ }^{28}$ É importante notar aqui que, apesar das tentativas de contato, não pude contar com a colaboração de qualquer conselheiro do segmento trabalhador contratado pela iniciativa privada. Assim, nenhum foi entrevistado. Apesar de lamentável, essa dificuldade, penso eu, reforça ainda mais a hipótese desse gargalo. 
ocorrendo uma coação dos gestores em cima dos trabalhadores, mas a gente via certa insegurança desses trabalhadores. Essa insegurança é até por conta da instabilidade. Muitas vezes, eu via que esses conselheiros não participavam da forma que queriam, porque tinham medo de perder os seus empregos". (entrevista com representante do usuário)

A baixa participação não parece se explicar, ainda, em razão de um desinteresse ínsito ao segmento trabalhador, como se simplesmente tivesse menos em jogo do que os demais: ao analisar as intervenções dos conseIheiros nas discussões em oito municípios brasileiros, Almeida (2010, p. 155) ressaltou como "em relação aos demais segmentos, os trabalhadores são também ativos na maioria das cidades". Considerando a relativamente grande "privatização da gestão" da saúde em São Paulo, os entrevistados parecem acertar seu diagnóstico a respeito do silêncio dos trabalhadores, ao menos em relação a esse município.

A instabilidade da maioria dos conselheiros do segmento trabalhador compromete a condição da "igualdade deliberativa" (Almeida e Cunha, 2011, p. 111). Apesar de fundamentais, procedimentos adequados para a inclusão de participantes não bastam: uma vez presentes na mesma sala, todos devem ainda ter as mesmas oportunidades de expor e fundamentar seus argumentos e reagir aos dos demais. Ou seja, deve existir efetiva igualdade também na capacidade de cada participante intervir na discussão. Para a deliberação ideal, nas palavras de Cohen (1997, p. 74), as partes devem ser iguais tanto de um ponto de vista formal (as regras não devem beneficiar um ou outro indivíduo ou grupo) quanto material (indivíduos ou grupos não devem sofrer desvantagens rela- tivas a recursos ou posições sociais). Nesse caso, há evidente desigualdade formal entre os segmentos.

\subsubsection{As nebulosas atribuições das supervi- sões de saúde}

Como visto, descentralização e regionalização são diretrizes da administração da saúde em São Paulo desde a retomada do SUS na gestão Marta Suplicy. No entanto, para Pinto, Spedo e Tanaka (2009a, 2009b, 2010), elas não se efetivaram. Em relação às coordenadorias e supervisões, destacam como a regulamentação vigente (disposta em portarias da Secretaria Municipal de Saúde) sequer define suas competências orgânicas ou organização interna. Em estudo de caso em uma supervisão, verificaram que seu papel se resume, dentro das possibilidades oficiais, à fiscalização da rede ambulatorial função a qual desempenha de forma limitada, por conta da falta de capacidade (Pinto, Spedo e Tanaka, 2009b, p. 1785).

Quando gestores conseguem uma atuação mais ativa, partem de acordos informais baseados em relações pessoais do tipo "quem é amigo de quem" - fato que eles mesmos identificam como falha de gestão. Assim, nas palavras de Pinto, Spedo e Tanaka (idem, p. 1787), verificou-se a "inexistência de práticas de planejamento locorregional os projetos eram definidos no nível central de SMS-SP e conduzidos pelo supervisor que, por sua vez, apresentava baixíssimo poder de interferência sobre os mesmos". Essa questão tem grande relevância para os conselhos das supervisões, na medida em que obscurece os contornos de suas competências (pois não podem decidir com força vinculante sobre assuntos que extrapolam os limites do nível administrativo na qual se inserem). De fato, a legislação sobre os con- 
selhos não define as define para além das vagas expressões "planejamento, avaliação, fiscalização e controle".

Essas observações são consistentes com problemas verificados em ambos os conselhos: entrevistados, especialmente do segmento da administração, relataram contínua confusão dos conselheiros quanto a quais assuntos podem ser objetos de ação das supervisões de saúde. Isso inclui, principalmente, a tendência dos usuários de trazerem e insistirem em questões que extrapolam as competências das supervisões: constantemente introduzem-se problemas de responsabilidade da secretaria municipal de saúde, das coordenadorias de saúde ou dos próprios equipamentos.

"O que eu acho que os conselheiros confundem um pouco é o poder de decisão. Por exemplo, todo governo tem diretrizes, tem um programa de metas, que são atribuições do governo. Dado isso, o que a gente faz? O que a gente faz é implantar, fazer acontecer o que foi definido pelo governo. (...) Os conselheiros muitas vezes querem mudar o programa, e isso não é atribuição do conselho". (entrevista com representante do segmento gestor)

"Se fala que cada unidade tem o seu conselho, que existe uma hierarquia, que quando não se dá conta dos problemas com o gerente da UBS, vai para a supervisão. (...) Mas as pessoas já querem jogar tudo para a supervisão". (entrevista com representante do segmento gestor)

"Uma das coisas que a gente tentava não colocar eram os problemas que surgiam no hospital, mas era impossível impedir. Eles sempre traziam as questões do hospital para a reunião do conselho da supervisão (...) eles acabavam confundindo isso." (entrevista com representante do segmento usuário)

Tal tendência poderia ser interpretada como tentativa dos usuários de defenderem seus interesses independentemente da instância administrativa na qual se encontram. No entanto, os conselheiros, como relatado em diversas entrevistas, podem atuar (e de fato atuam) de forma a exercer pressão sobre níveis administrativos superiores e inferiores, sem, contudo, necessariamente proporem-se a trazer pautas sobre as quais não podem decidir. O problema, segundo representantes da administração está, mais precisamente, na confusão dos usuários quanto aos poderes do conselho. Poderia-se atribuir essas dúvidas a falta de conhecimento, mas, considerando como a maioria dos entrevistados passou por cursos de capacitação ${ }^{29}$ e já repetiu mandatos como conselheiros, além de que todos afirmaram considerar seus pares como preparados para discussões complexas ${ }^{30}$, a explicação se mostra insuficiente. Assim, retornamos ao motivo mais aparente: os conselheiros não sabem precisar as competências dos conselhos porque essa é uma tarefa impossível de um ponto de vista formal (pela falta de regulamentação) ou fático (pelo fato da ação das supervisões variar conforme acordos informais).

A persistente confusão quanto às atribuições dos conselhos deteriora sua capacida-

\footnotetext{
29 Todos os conselheiros, em quaisquer níveis administrativos, têm a oportunidade de passar pelos cursos oferecidos pela Escola Técnica do SUS. Esta é uma subdivisão da Escola Municipal de Saúde, a qual tem como uma de suas atribuições expressas a administração da educação permanente em participação social na cidade (Decreto Municipal 52.514/11). Segundo um documento interno elaborado pelo Grupo de Trabalho para Educação Permanente do Controle Social da Escola Municipal de Saúde, entre 2003 e 2013 foram formadas 233 turmas, das quais participaram 4.748 conselheiros.

${ }^{30}$ A qualificação dos conselheiros é um ponto importante na literatura - em sua revisão, Tatagiba (2002:69-73) destaca o "reconhecimento unânime da falta de capacitação dos conselheiros (...) para uma intervenção mais ativa no diálogo deliberativo no interior dos conselhos". Como explicado acima, a falta de capacitação não parece ser um problema nos conselhos de saúde de São Paulo.
} 
de de "conclusividade" (Almeida e Cunha, 2011, p. 111). Em algum momento, a deliberação deve terminar e gerar uma decisão - em contextos reais, normalmente através do mecanismo do voto. A decisão, lembremos, será idealmente considerada, se não unânime, justificável para todos os participantes. Para Araujo (2004), o período de deliberação pode ser concebido como um momento de construção de um estoque alternativas mutuamente justificadas, sendo uma delas escolhida no momento agregativo de votação. No caso dos conselhos de supervisão, não há clareza a respeito de quais assuntos podem entrar em pauta e quais soluções podem compor o "estoque de alternativas".

4.1.3. Poderes de fato não vinculantes (e o real padrão decisório)

Como explicado anteriormente, os conseIhos gestores das supervisões técnicas de saúde, em princípio, têm poder vinculante (e não apenas consultivo). Isso significa que, uma vez tomadas e publicizadas as decisões, deveriam se tornar vinculantes para a esfera administrativa sob sua autoridade. No entanto, em parte por conta de uma série de arranjos inter-relacionados, isto não ocorre de fato nos conselhos das supervisões de Campo Limpo e Cidade Tiradentes. Seu impacto na política de saúde local se dá através de padrões institucionais distintos e muitas vezes informais.

Em primeiro lugar, as decisões não são publicadas em Diário Oficial. Quando propostas como vinculantes, de acordo com a Quarta Diretriz, XII, da Resolução 453 do Conselho Nacional de Saúde (e, no caso do Campo Limpo, seu próprio regimento interno), as decisões deveriam ser formalizadas em resoluções, homologadas pela autoridade responsável (no caso, o supervisor de saúde) e publicadas em diário oficial. No entanto, com exceção de assuntos relacionados ao regimento interno, ao regimento eleitoral e aos nomes dos conselheiros eleitos, nenhum dos conselhos da cidade segue essa prescrição.

Ao identificar a mesma tendência em conselhos de assistência social, Cunha (2010, p. 118) insiste na importância da publicização das decisões em meios institucionais, pois, em princípio, são passíveis de contestação jurídica. A falta da formalização poderia, assim, deixar de conferir juridicamente às decisões seu caráter vinculante e obstar eventuais tentativas de efetivação das decisões por via judicial, deixando sua implementação, em suas palavras, "a mercê do gestor"31. Há, ainda, um problema de transparência, na medida em que as decisões escapam aos meios de divulgação tradicionais.

Em segundo lugar, entrevistados apontaram que não existem instrumentos institucionais de acompanhamento e efetivação das decisões. Quando realizado, tal esforço recai na prática sobre os próprios conselheiros, os quais organizam-se informalmente entre si próprios ou recebem relatos de outros usuários do sistema de saúde. Esse não é um problema exclusivo dos conselhos das supervisões: conforme discute Tatagiba (2002, p. 95), a legislação e as regras dos conselhos individuais não costumam prever formas de garantir o cumprimento das decisões, problema este que atribui a uma reconhecida "institucionalização incompleta dos conselhos".

Em terceiro lugar, e de forma relacionada

31 A possibilidade judicialização de eventuais descumprimentos das decisões não foi levantada por conselheiros e parece nunca ter se concretizado no município. No entanto, vale mencionar que, como parte da administração direta, os conselhos não possuem capacidade postulatória e não podem ingressar em juízo. Em uma pesquisa jurisprudencial, Oliveira (2014) demonstra que conselhos tiveram a capacidade postulatória negada continuamente no TJRS. 
ao gargalo anterior, é difícil imaginar que os conselhos consigam decidir de forma vinculante sem a existência de atribuições definidas e sem que as supervisões contem minimamente com recursos próprios e com capacidade de planejamento. Assim, como destacaram entrevistados, a implementação das deliberações depende menos do cumprimento de ritos decisórios e mais de esforços de justificação, barganha e pressão frente a outros órgãos da gestão municipal, em especial a Secretaria Municipal de Saúde - a qual, como discutido anteriormente, concentra os recursos e a capacidade de planejamento da política municipal. Como ressaltaram representantes do segmento gestor:

"Tinha até um conselheiro que entedia dessa parte, e ele foi ver como funcionava essa parte do dinheiro, e foi até engraçado... uma vez esse conselheiro falou assim: 'puxa, a gente pensava que aqui vocês mexessem direto com o dinheiro, mas entendi que vocês são pedintes como nós aqui'. Eu achei muito interessante, e disse, 'é, você chegou na questão, nós também somos pedintes, a gente também pede coisas para a secretaria o tempo inteiro'. A gente tem que apresentar nossas necessidades, embasar bem, justificar, e mandar isso bem consistente, pra que as pessoas que recebam isso entendam bem a nossa necessidade, e, em cima de uma coisa bem organizada, nos ajudem". (entrevista com representante do segmento gestor)

"Uma das questões que o pessoal pediu foi essa unidade [de saúde]. A gente colocou isso no papel, mas a gente teve que levar isso para secretaria. Lá que você tem uma discussão do que é viável e do que não viável". (entrevista com representante do segmento gestor)
"Acho que [o conselho] também deveria ter um recurso próprio, o recurso ser descentralizado, pro conselho ter mais autonomia. Fica muito centralizado em finanças, e pra acessar esse recurso, é muito difícil. A gente não tem nem noção. É da coordenadoria pra lá. Secretaria, acho. É fechado." (entrevista com representante do segmento usuário)

Os reais processos de efetivação variam de acordo com o objeto da decisão tomada e não são minimamente perceptíveis a partir da leitura da regulamentação formal. Entrevistados narraram algumas formas pelas quais se mobilizaram, incluindo o diálogo com a SMS com o intermédio de conselheiros do Conselho Municipal, pressão direta sobre o secretário de saúde e negociações com as Organizações Sociais e com as gestões dos hospitais. Na relação com a SMS, os conselhos têm importância, para Coelho (2013, p. 9), no apoio às demandas levadas pelos supervisores de saúde: em um contexto de competição pelos recursos orçamentários entre as supervisões, o aval da sociedade civil faz diferença. Não à toa, a autora considera conexões dos conselhos com autoridades institucionais e políticas como uma das variáveis explicativas da efetivação de demandas.

A informalidade na influência sobre a gestão da saúde não significa que os conselhos das supervisões tenham impacto negligenciável nos rumos das políticas em suas regiões. No caso de Campo Limpo, entrevistados atribuem à atuação do conselho o crescimento da quantidade de equipamentos na região e instalação Centros de Atenção Psicossocial (CAPS) do tipo "Alcool e Drogas" e "Infantil". Em Cidade Tiradentes, conselheiros apontam para a intensificação do Programa Mais Médicos, a construção 
do Hospital Cidade Tiradentes e ampliação na quantidade de equipamentos CAPS. De fato, essas opiniões se alinham com o quadro traçado por Coelho (2013), no sentido de que, no agregado, a atuação dos conselhos das supervisões tem contribuído para a redução das desigualdades entre regiões centrais e periféricas no provimento de serviços de saúde em São Paulo. No entanto, como destaca a própria autora, a desigualdade entre regiões periféricas se reforçou, pois nem todos os conselhos possuem a mesma capacidade de mobilização.

Não sugiro que reformas na estrutura formal dos conselhos e das supervisões por si só levariam a modificações previsíveis na configuração institucional aqui descrita. Isso porque resulta de um longo e complexo processo de criação e mudança institucional cuja análise demandaria uma pesquisa original. No entanto, é difícil imaginar que, alterasdos os atuais arranjos - como a indefinição das atribuições das supervisões, a ausência de dotação orçamentária das mesmas, a concentração de poderes na SMS, a não publicação das decisões em Diário Oficial e a inexistência de mecanismos de acompanhamento das decisões - os padrões decisórios dos conselhos permaneceriam os mesmos.

De qualquer maneira, se a real operação dos conselhos não invalida sua importância, representa um problema normativo: conflita com a concepção de que os processos deliberativos devem levar a uma decisão vinculante (Gutmann e Thompson, 2004, p. 3; Cohen, 2007, p. 219) ${ }^{32}$. Com isto, não quero

\footnotetext{
${ }^{2} \mathrm{O}$ critério da "vinculação" é controverso entre teóricos como condi ção para a deliberação. Almeida e Cunha (2011) não o incluem em sua sistematização e Mansbridge (2015) explicitamente o exclui de sua definição minimalista. No entanto, como a própria Mansbridge (2015, p. 33) explica, a exclusão se justifica unicamente para que a definição abarque processos de deliberação que não se voltam à legitimidade da atividade estatal. Como neste caso lidamos com uma instituição estatal e com poderes pretensamente vinculantes, faz sentido aplicar o critério.
}

dizer que as discussões no interior dos conselhos se restrinjam idealmente à tomada de decisões - como destacou uma gestora, eles também têm uma importante função como espaços de consulta e informação. Há, no entanto, um problema de legitimidade da ação estatal, uma vez que os processos decisórios efetivamente vinculantes na gestão da saúde driblam os espaços criados para os controlar e democratizar.

4.2. Uma estratégia de evolução institucional: identificação e difusão de inovações institucionais

Mesmo com um esforço de identificação de gargalos, a tarefa de propor soluções deve ser desempenhada com cuidado: como mostra a experiência com reformas jurídico-institucionais ${ }^{33}$, os resultados atingidos não raras vezes destoam do esperado - em algumas situações, com efeitos altamente indesejáveis. Neste artigo, adota-se uma postura relativamente mais conservadora. Sustento que o desempenho legítimo dos conselhos de saúde do município pode ter ganhos com, nos termos de Goodin (1996, p. 28), um "método para desenhar instituições" capaz de viabilizar a adaptação de desenhos a seus contextos, garantir revisibilidade das soluções adotadas e lidar com a multiplicidade de atores que integram a rede de participação em saúde. Para isso, emprega-se os conceitos de "difusão institucional" e "governança experimentalista".

Considerando sua turbulenta história no município de São Paulo, os conselhos de saúde passam, em seu conjunto, por um relativamente longo período de estabilidade institucional desde a gestão Marta Suplicy. Suas características fundamentais encontram-se estabilizadas em instrumentos

33 Para uma revisão abrangente de reformas jurídico-institucionais em diversas áreas, ver Prado e Trebilcock (2011). 
legislativos pouco flexíveis (leis federais e municipais), e mudanças radicais parecem bloqueadas, ao menos nos curto e médio prazos. Apesar disso, há ainda espaço para consideráveis variações em diversos arranjos formais e informais dos conselhos, e, como visto durante no curso do artigo, tais diferenças podem ter impactos relevantes no desempenho dessas instituições.

Mesmo sem completo controle sobre todas as suas regras, os conselhos podem desenvolver soluções institucionais próprias para seus problemas. O caso de Campo Limpo, em especial, ilustra possibilidades de adaptação. Como reação às péssimas condições anteriores, evoluíram nos últimos anos a forma de condução das reuniões, o processo de composição da pauta, o modo construção das atas, a participação de não conseIheiros nas reuniões e a rotina de trabalho das comissões (o que explica o grau de detalhamento formal do regimento e do regulamento eleitoral do conselho). Um exemplo ilustrativo é a Comissão de Atenção Básica: desativada até 2006 (apesar de formalmente existente), ela fiscaliza os equipamentos de saúde da região. Com o acúmulo de experiência, ao invés de visitas com aviso prévio à gerência local, os conselheiros passaram a realizar entrevistas surpresa com usuários e desenvolveram um questionário padrão. Essas experimentações se alinham com a percepção de Coelho et al. (2010, p. 338), de que os conselhos de saúde das supervisões com menor capacidade de mobilização têm discutido internamente oportunidades de reforma (em comparação, o conselho de Cidade Tiradentes pouco se alterou nos últimos anos).

Sob certas restrições, os conselhos podem continuar a experimentar e aprender com variações institucionais. Essa é uma consta- tação importante, pois indica a possibilidade de adaptação às mutáveis necessidades contextuais (Sabel e Zeitlin, 2012). Também significa que o quadro jurídico-institucional dos conselhos de saúde de São Paulo cumpre adequadamente a tarefa de garantir a estabilidade necessária para evitar rupturas bruscas e, ao mesmo tempo, permitir flexibilidade suficiente para não travar a experimentação (Coutinho, 2014, p. 171).

Apenas no município de São Paulo, existem 25 conselhos de supervisão e aproximadamente 400 conselhos de equipamentos lidando de suas próprias maneiras com diversos problemas compartilhados. Há, nessa variedade de instituições similares operando de forma autônoma, uma interessante oportunidade de evolução institucional conjunta: a difusão organizada de arranjos funcionais.

A difusão é um mecanismo de mudança institucional (Pierson, 2004, p. 138). Ele opera mediante a transferência de conhecimentos entre organizações, levando algumas a adotarem práticas desenvolvidas em outras. Em situações ideais, a difusão provê um atalho no processo de calibração dos arranjos, eliminando a necessidade de cada organização desenvolver suas próprias soluções quando outras encararam problemas similares e já o fizeram. Em outras palavras, ocorre a transferência do aprendizado gerado através das experimentações. No atual caso isso poderia significar, por exemplo, o aproveitamento do questionário desenvolvido pela Comissão de Atenção Básica de Campo Limpo em outros conselhos.

As entrevistas indicaram algumas formas através das quais conhecimentos se difundiram na rede de conselhos de São Paulo. Entrevistados com experiência em vários 
conselhos afirmaram já terem sugerido mudanças em uns com base na experiência adquirida em outros. Um dos entrevistados do segmento administração explicou como pesquisou diversos regimentos internos para elaborar sugestões de reforma para o seu conselho. Assessores de gestão participativa dos conselhos de supervisão, ainda, mencionaram a realização de reuniões com conselheiros e burocratas de outras regiões para discutirem a possibilidade de criação de comissões de ética internas, formas de garantir a participação dos trabalhadores e reformulações da política municipal de educação permanente da sociedade civil.

Essas formas de difusão, no entanto, mesmo quando realizadas intencionalmente, não se inserem em um uma estrutura institucional de reconhecimento e transferência de inovações institucionais ${ }^{34}$. Sobre essa questão, para Fung (2004) e Sabel e Zeitlin (2012), autoridades centralizadas podem estruturar mecanismos para conectar organizações similares e permitir que elas se comparem, aprendam com a experiências compartilhadas e elaborem soluções conjuntas. Isso, no entanto, sem bloquearem a autonomia das unidades descentralizadas. $O$ caso destrinchado por Fung (idem, p. 76) tem aqui especial relevância, pois narra como a implementação local de mecanismos de participação nas políticas de educação e policiamento da cidade de Chicago foram energizadas por gabinetes centralizados. Para o autor, as unidades locais tornaram-se mais autônomas, no sentido de contarem com maior capacidade de atingir seus objetivos.

Ao destravar bloqueios institucionais, esse tipo de método tem o potencial de contri${ }^{34}$ A discussão sobre as comissões de ética ocorreu em reuniões periódicas dos assessores das supervisões da região sul e o problema da participação dos trabalhadores foi abordado em grupos da região leste. As deliberações a respeito da reformulação da política de educação permanente ocorrem a nível municipal sob a coordenação da Escola Municipal de Saúde, mas esgotam-se nesse tema. buir para a pavimentação de um caminho de evolução sustentada. Ao empregar acordos informais, instrumentos de "soft law" (como recomendações) e mecanismos de comparação entre os conselhos, pode fazê-lo sem recorrer necessariamente à imposição de normas inflexíveis e nem sempre adaptadas aos contextos que deveriam regular. Determinados arranjos podem eventualmente ser impostos, mas após um processo de construção e discussão baseado na identificação de problemas reais - ou seja, de maneira compatível com os princípios deliberativos. Esse tipo de trajetória de evolução tem ainda o mérito de operar de forma gradual e responsiva aos custos de mudança institucional ${ }^{35}$.

Tal tarefa pode ser cumprida por estruturas já existentes, como a Comissão InterconseIhos do CMS e a Assessoria de Gestão Participativa da SMS. Até o momento, indicam as entrevistas, essas estruturas têm sido empregadas de forma principalmente fiscalizatória (garantindo que os conselhos de supervisão e dos equipamentos não afrontem a legislação existente) e reativa (respondendo a denúncias e a pedidos de auxílio, por exemplo, na organização de eleições). Os conselhos de Campo Limpo e de Cidade Tiradentes se desenvolveram nos últimos anos com pouco envolvimento desses órgãos (com exceção de raros momentos nos quais algum ator a solicitou) ou contato com outros conselhos de supervisão. Essa falta de comunicação impõe perdas de oportunidades, pois, como destacam Cohen e Sabel (1997, p. 325), "unidades locais, operando de forma isolada, não têm a capacidade de explorar a completa gama de soluções possíveis".

${ }^{35}$ Baseando-se em teorias de dependência da trajetória, Prado e Trebilcock (2009) sugerem que esforços de reforma jurídico-institucional devem levar em conta o sequenciamento e a juscala de sua impl mentação. Para os autores, mudanças ar tores, mudanças amplas e bruscas tendem a falhar. 


\section{Conclusão}

Este artigo consistiu em um esforço de mapeamento e crítica das escolhas jurídico-institucionais que constituem os conselhos gestores das supervisões técnicas de saúde do município de São Paulo. O desenho da rede de conselhos na gestão da saúde na cidade, procurou-se mostrar, é especial mesmo em meio à "ecologia" de instituições participativas existente no país. Isso por conta de seu processo de formação (que antecede a redemocratização) e seu grau de descentralização e capilaridade. Graças à liberdade em definir seus próprios regimentos internos e regulamentos eleitorais, o desenho formal dos conselhos de supervisão pode variar em dimensões relevantes (como em seus mecanismos de seleção de participantes), compondo instituições com características distintas.

Para além da reconstituição de seus desenhos formais, o artigo discutiu os conselhos "em ação" - processo no qual desvelou dinâmicas institucionais não observáveis "nos livros". Algumas destas, argumentou-se, têm relação direta com as escolhas jurídicas-formais e possuem impactos negativos nas capacidades de legitimidade: o regime de contratação dos trabalhadores das organizações de saúde inibe sua fala, as nebulosas atribuições dos conselhos confundem o processo de deliberação e a efetiva falta de poder vinculante se relaciona com uma dinâmica informal na tradução das demandas em políticas. Além disto, e considerando as características únicas da participação na cidade, sugeriu-se uma estratégia de aprimoramento institucional ainda inexplorada baseada na literatura da governança experimentalista.

Com esta contribuição, busca-se demons- trar que o estudo das instituições - e, mais especificamente, das instituições participativas - está aberto a relevantes contribuições por parte dos juristas. As falhas apontadas no artigo envolvem questões como regime de contratação, divisão de competências e poderes decisórios de órgãos públicos. Não é plausível, dessa forma, argumentar que não se tratam de escolhas jurídicas e que não se incluem no espectro de preocupações acadêmicas e profissionais dos juristas. Este esforço certamente depende de algum grau de insubordinação a rígidas e arbitrárias divisões disciplinares, na medida em que demanda aproximação de teorias e métodos desenvolvidos em outros campos do conhecimento. Antes de deletéria, tal aproximação deve trazer diálogos proveitosos para as demais ciências sociais e para o próprio direito.

\section{REFERÊNCIAS}

Almeida, D.R (2010). Metamorfose e representação política: lições práticas dos conselhos municipais de saúde do Brasil. In: Avritzer, L. A dinâmica da participação local no Brasil. São Paulo: Cortez.

Almeida, D.R.; Cunha, E.S.M. (2011). A análise da deliberação democrática: princípios, conceitos e variáveis relevantes. In: Pires, R.R. Efetividade das instituições participativas no Brasil: estratégias de avaliação. Brasília: IPEA

Almeida, D.R.; Cunha, E.S.M. (2014). Conselhos de políticas e desenho institucional: potencialidades e limites do isomorfismo institucional nas áreas de saúde e da assistência social no Brasil. In: Cunha, E.S.M.; Theodoro, H.D. Desenho institucional, democracia e participação: conexões teóricas e possibilidades analíticas. Belo Horizonte: D’Placido.

Araujo, C. (2004). Razão pública, bem comum e decisão democrática. In: Coelho, V.S.; Nobre, M. Participação e deliberação: teoria democrática e experiências institucionais no Brasil contemporâneo. São Paulo: Ed. 34.

Brasil (2004). Saúde mental no SUS: os centros de 
atenção psicossocial / Ministério da Saúde, Secretaria de Atenção à Saúde, Departamento de Ações Programáticas Estratégicas. - Brasília: Ministério da Saúde. Chambers, S. (2013). Deliberative democratic theory. Annual Review of Political Science, 6, 307-326.

Castro, H. (2017). O direito nas instituições de deliberação democrática. Revista da Faculdade de Direito do Sul de Minas, 33(2), 190-227.

Coelho, V.S. (2007). A democratização dos conselhos de saúde: o paradoxo de atrair não aliados. Novos Estudos, 78, 77-92.

Coelho, V.S. (2013). What did we learn about citizen involvement in the health policy process: lessons from Brazil. Journal of public deliberation, 9(1), 1-17.

Coelho, V.S. et al. (2010). Mobilização e participação um estudo sobre as dinâmicas de conselhos de saúde da cidade de São Paulo. In: Avritzer, L. A dinâmica da participação local no Brasil. São Paulo: Cortez.

Cohen, J. (1997). Deliberation and democratic legitimacy. In: Bohman, J.; Regh, W. Deliberative democracy: essays on reasons and politics. Cambridge: The MIT Press.

Cohen, J.; Sabel, C. (1997). Directly-deliberative polyarchy. European Law Journal, 3(4), 313-342.

Cohn, A.; Elias, P.E. (1998). O plano de assistência à saúde do município de São Paulo: uma modalidade alternativa de gestão? Revista de Administração, 33(1), 44-50.

Contreiras, H.; Matta, G.C. (2015). Privatização da gestão do sistema municipal de saúde por meio de organizações sociais na cidade de São Paulo, Brasil: caracterização e análise da regulação. Cadernos de Saúde Pública, 31(2), 285-297.

Cortês, S.V. (1995) User participation and reform of the Brazilian Health System: the case of Porto Alegre. Tese (Doutorado) - Departamento de Política Social e Administração da London School of Economics, Londres.

Coutinho, D.R. (2014). Direito econômico e desenvolvimento democrático: uma abordagem institucional. Tese para Concurso de Professor Titular - Faculdade de Direito da USP, São Paulo.

Coutinho, J. (1997). A participação popular na gestão da saúde de São Paulo. Lutas Sociais, 2, 125-138.

Cunha, E.S.M. (2010). Inclusão social e política: o desafio deliberativo dos conselhos municipais de assistência social. In: Avritzer, L. A dinâmica da participação local no Brasil. São Paulo: Cortez.

Cyrino, P.C.B.; Liberati, W.D. (2003). Conselhos e Fun- dos no Estatuto da Criança e do Adolescente. São Paulo: Malheiros Editores.

Dahl, R.A. (2006) A preface to democratic theory. 3 ed. Chicago: The Chicago University Press.

Dryzek, J. (1987). Discursive designs: critical theory and political institutions. American Journal of Political Science, 31(3), 656-679.

Dryzek, J. (2000). Deliberative democracy and beyond: liberals, critics, contestations. New York: Oxford University Press.

Edelman, L.; Suchman, M. (1997). Legal rational myths: the new institutionalism and the law and society tradition. Law and Social Inquiry, 21, 903-941.

Ehrlich, E. (1936). Fundamental principles of the sociology of law. Cambridge: Harvard University Press.

Faria, C.F.; Ribeiro, U.C. (2010). Entre o legal e o real: o que dizem as variáveis institucionais sobre os conseIhos municipais de políticas públicas? In: Avritzer, L. A dinâmica da participação local no Brasil. São Paulo: Cortez.

Fishkin, J. (2013). Deliberation by the people themselves: entry points for the public voice. Election Law Journal, 12(4), 490-507.

Fung, A. (2003). Recipes for public spheres: eight institutional design choices and their consequences. The Journal of Political Philosophy, 11(3), 338-367.

Fung, A. (2004). Empowered participation: reinventing urban democracy. Princeton: Princeton University Press.

Gaventa, J. (2004). Prefácio. In: Coelho, V.S.; Nobre, M. Participação e deliberação: teoria democrática e experiências institucionais no Brasil contemporâneo. São Paulo: Ed. 34.

Goodin, R. (1998). Institutions and their design. In: Goodin, R. The theory of institutional design. Cambridge: Cambridge University Press.

Gutmann, A.; Thompson, D. (2004). Why deliberative democracy? New Jersey: Princeton University Press.

Hodgson, G. (2006) What are institutions? Journal of Economic Issues, 40(1), 1-25.

IBGE. Relatório: Perfil dos Municípios Brasileiros 2012. Rio de Janeiro, 2013.

IBGE. Relatório: Perfil dos Municípios Brasileiros 2013. Rio de Janeiro, 2014.

Jacobi, P. (1993). Movimentos sociais e políticas públicas: demandas por saneamento básico e saúde. 2 ed. São Paulo: Cortez.

Junqueira, V. Saúde na cidade de São Paulo (1989 a 2000). 2 ed. São Paulo, Pólis/PUC-SP, 2002. (Observa- 
tório dos Direitos do Cidadão: acompanhamento e análise das políticas públicas da cidade de São Paulo, 3).

Levy, R. (2013).The law of deliberative democracy: seeding the field. Election Law Journal, 12(4), 355-371. Lima, P.P.F.; Souza, C.H.L.; Teixeira, A.C.C. (2012). Arquitetura da participação no Brasil: uma leitura das representações políticas em espaços participativos nacionais. Brasília: IPEA, 2012. (Texto para discussão n. 1735).

Lopes, J.R.L. (2000). Os conselhos de participação popular: validade jurídica de suas decisões. Revista de Direito Sanitário, 1(1), 23-35.

Maarse, H. (2006). The privatization of health care in Europe: an eight-country analysis. Journal of Health, Politics, Policy and Law, 31(5), 981-1014.

Macaulay, S. (2005). The new versus the old legal realism: "things ain't what they used to be". Wisconsin Law Review, 2005(2), 365-403.

Mansbridge, J. et al. (2010). The place of self-interest and the role of power in deliberative democracy. Journal of Political Philosophy, 18(1), 64-100.

Mansbridge, J. (2015). A minimalist definition of deliberation. In: Heller, P.; Rao, V. Deliberation and development: rethinking the role of voice and collective action in unequal societies. Washington: Banco Mundial.

Neder, C.A.P. (2001). Participação e gestão pública: a experiência dos movimentos populares de saúde no município de São Paulo. Dissertação (Mestrado) Faculdade de Ciências Médicas da Universidade de Campinas, Campinas.

Nelken, D. (1984). Law in action or living law? Back to the beginning in sociology of law. Legal Studies, 4(2), 157-174.

Öberg, P. (2002). Does administrative corporatism promote trust and deliberation? Governance: an International Journal of Policy, Administration and Institutions, 15(4), 455-475.

Oliveira, C.C.F. (2014). Os conselhos municipais nas controvérsias jurisprudenciais do TJRS e STF nos últimos anos. Revista da Procuradoria Geral do Município de Porto Alegre, 25, 35-58.

Parkinson, J. (2006). Deliberating in the real world: problems of legitimacy in deliberative democracy. Oxford: Oxford University Press.

Perez, M.A. (1996) Institutos de participação popular na administração pública. Dissertação (Mestrado) Faculdade de Direito da USP, São Paulo.

Pierson, P. (2004) Politics in time: history, institutions and social analysis. Princeton: Princeton University Press.

Pinto, N.R.S.; Spedo, S.M.; Tanaka, O.Y. (2009a). Política de saúde e gestão no processo de (re)construção do SUS em município de grande porte: um estudo de caso de São Paulo, Brasil. Cadernos de Saúde Pública, 25(4), 927-938.

Pinto, N.R.S.; Spedo, S.M.; Tanaka, O.Y. (2009b). O desafio da descentralização do Sistema Único de Saúde em município de grande porte: o caso de São Paulo, Brasil. Cadernos de Saúde Pública, 25(8), 1781-1790.

Pinto, N.R.S.; Spedo, S.M.; Tanaka, O.Y. (2010). A regionalização intramunicipal do Sistema único de Saúde (SUS): Um estudo de caso do município de São Paulo-SP, Brasil. Saúde e Sociedade, 19(3), 533-546.

Pires, R.R.; Vaz, A. (2012). Participação como método de governo? Um mapeamento das "interfaces socioestatais" nos programas federais. Rio de Janeiro: IPEA (Texto para discussão n. 1707).

Pistor, K. et al. (2017). Legal institutionalism. Journal of Comparative Economics, 45, 188-200.

Pound, R. Law in books and law in action. American Law Review, 44, 12-36.

Prado, M.M.; Trebilcock, M. (2009). Path dependence, development, and the dynamics of institutional reform. University of Toronto Law Journal, 59, 341-380.

Prado, M.M.; Trebilcock, M. (2011). What makes poor countries poor? Institutional determinants of development. Cheltenham: Edward Elgar.

Sabel, C.; Zeitlin, J. (2012). Experimentalist governance. In: Levi-Faur, D. The Oxford handbook of governance. Oxford: Oxford University Press.

Sader, E. (1998). Quando novos personagens entram em cena: experiências, falas e lutas dos trabalhadores da Grande São Paulo, 1970-1980. Rio de Janeiro: Paz e Terra.

Santos, A.; Trubek, D. (2006). The third moment in law and development theory and the emergence of a new critical practice. In: Santos, A.; Trubek, D. The new law and economic development: a critical appraisal. Cambridge: Cambridge University Press.

Smith, R. (2008). Historical institutionalism and the study of law. In: Caldeira, G. et al. The Oxford handbook of law and politics. Oxford: Oxford University Press.

Tatagiba, L. (2002). Os conselhos gestores e a democratização das políticas públicas no Brasil. In: Dagnino, E. Sociedade civil e espaços públicos no Brasil. São Paulo: Paz e Terra.

Tatagiba, L. (2004). A institucionalização da partici- 
pação: os conselhos municipais de políticas públicas na cidade de São Paulo. In: Avritzer, L. A participação em São Paulo. São Paulo: Editora Unesp.

Unger, R.M. (2015). The critical legal studies movement: another time, a greater task. Londres: Verso.

Vitale, D. (2004). Democracia direita e poder local: a experiência brasileira do orçamento participativo. In: Coelho, V.S.; Nobre, M. Participação e deliberação: teoria democrática e experiências institucionais no Brasil contemporâneo. São Paulo: Ed. 34.

Young, I.M. (2000). Inclusion and democracy. Oxford: Oxford University Press.

Data de submissão: 13/10/2017

Data de aceite: 02/06/2019 